\title{
The nature of cross-modal color-word interference effects
}

\author{
EMILY M. ELLIOTT and NELSON COWAN \\ University of Missouri, Columbia, Missouri \\ and \\ FERNANDO VALLE-INCLAN \\ University of La Comunã, La Comũa, Spain
}

\begin{abstract}
Cowan and Barron (1987) and Cowan (1989b) reported that color-naming performance was slowed by spoken color names drawn from the same set but presented in an order unrelated to the printed colors. Although Miles, Madden, and Jones (1989) and Miles and Jones (1989) were unable to replicate this cross-modal effect, it is replicated here in two experiments with much better experimental control than before. However, the effect is shown to depend upon the relative timing of the color and word in a way that conflicts with the theoretical account that Cowan and Barron offered. While Cowan and Barron suggested that an irrelevant color word would contaminate the response set if this word occupied short-term memory when the color was about to be named, it appears that interference actually occurs only if the memory representation was formed very recently and had not been inhibited. Further implications for processing are discussed.
\end{abstract}

Stroop's (1935) seminal research showed that the task of naming ink colors was slowed if each color of ink formed a color word that did not match the correct response. Most of the numerous studies further exploring that effect (reviewed recently by MacLeod, 1991, 1992) have provided conflicting cues within the visual modality (as Stroop did) or in a few cases within the auditory modality (Green \& Barber, 1981; McClain, 1983). However, Cowan and Barron (1987) found that the task of naming visually presented colors was slowed by the concurrent presentation of an audiotape containing a random sequence of spoken color words drawn from the same set as the correct responses. Audiotapes with noncolor words had no such effect on color naming. This cross-modal effect is theoretically important because it demonstrates that subjects cannot voluntarily restrict lexical processing to the visual modality. Cowan and Barron used these and concomitant results (e.g., the additivity of visual and cross-modal interference) to argue for "a description of processing in which multiple verbal items enter a prespeech buffer and a selection mechanism examines buffer items in parallel." However, a controversy has followed the initial report.

Miles, Madden, and Jones (1989) failed to replicate the cross-modal effects reported by Cowan and Barron (1987), but Cowan (1989b) pointed out ways in which the method of the original study had not been reproduced

This work was supported by NIH Grant R01 HD-21338 awarded to N.C. We thank John Flowers, Denny LeCompte, and an anonymous reviewer for suggestions. Address reprint requests to N. Cowan, Department of Psychology, 210 McAlester Hall, University of Missouri, Columbia, MO 65211 (e-mail: psycowan@showme.missouri.edu). faithfully. Miles and Jones (1989) briefly stated that they reproduced the method more faithfully and still failed to find the cross-modal interference, but Cowan (1989a) reported a replication with a similar method. Thus, reports of the success of this procedure have been mixed.

It seems noteworthy that the original study and the successful and failed replications all suffered from some important methodological limitations. Rather than being obtained for each visually presented color individually, reaction times were obtained for pages each of 100 items. Also, because the spoken channel was not synchronized with the visual stimulus, the timing of audiovisual presentation was variable. A side effect of this presentation method is that the spoken color word closest in time to a particular visual item or a particular response was, about one fifth of the time, the same color rather than a conflicting color. This could have made the auditory channel seem sometimes relevant and therefore more difficult to ignore. Perhaps these factors contributed to the failures to replicate.

There has been another, more recent study of crossmodal color-word interference. Shimada (1990) presented colors to be named one at a time (green, red, or blue), and each color was accompanied by an auditory stimulus with an onset varying from $200 \mathrm{msec}$ before to $200 \mathrm{msec}$ after the onset of the color. The auditory stimuli were (a) a color word matching the correct response, (b) a color word not matching the response but drawn from the response set (e.g., the color green accompanied by either the word "red" or the word "blue"), (c) the word "white," or (d) a buzzer sound. The results showed a large effect of the congruent stimuli but not much difference between the other conditions. Responses in the two incongruent color- 
word conditions (b and c) were, however, $18-20 \mathrm{msec}$ per word slower than in the buzzer condition when the auditory stimulus onset coincided with the color onset or followed it slightly, an effect magnitude similar to what Cowan and Barron (1987) observed. Unfortunately, this experiment did not include what are, from our viewpoint, the most important control stimuli: noncolor words. Presentation of the word "white" was considered a neutral condition, but it is of course a color. To examine colorword interference, the specific effect of hearing a color word must be compared with the effect of hearing another word that has little or no color connotation.

In the two experiments of the present study, therefore, we have replicated the cross-modal interference effect with a more precise, technically sophisticated method than Cowan and Barron (1987), Cowan (1989a), Miles et al. (1989), or Miles and Jones (1989) used. Within this method, individual response times were recorded for each visual color presentation, and the timing between the auditory and visual presentations was controlled.

We manipulated the delay between the onsets of auditory and visual stimuli. In one condition, the word onset was $500 \mathrm{msec}$ before the color onset. According to a large body of previous work on memory for speech (e.g., Baddeley, 1986; Cowan \& Saults, 1995), this interval should allow time for the word to be processed (e.g., recognized) before the color arrives, and yet the interval should be short enough for a temporary memory representation still to be in an active state when the color arrives. In the other condition, the word and color onsets were simultaneous. According to the theoretical description of Cowan and Barron (1987), an effect would be expected with a 500msec onset asynchrony and possibly with a 0 -msec asynchrony also if the word could be recognized and stored in memory quickly enough.

Previous studies of Stroop-like interference with visual as opposed to auditory interfering stimuli lead to a different expectation, however. They have produced the strongest effects with interfering stimuli presented from $100 \mathrm{msec}$ before to $100 \mathrm{msec}$ after the target stimuli. In these studies, an interfering stimulus as long as $500 \mathrm{msec}$ before the target produced very little interference (Flowers, 1990; M. O. Glaser \& W. R. Glaser, 1982; W. R. Glaser \& Düngelhoff, 1984; Goolkasian, 1981; Sugg \& McDonald, 1994).

One account of these results is that it is not enough for the interfering stimulus to be present in a vivid memory store when the target is processed as Cowan and Barron (1987) proposed; instead, the processing of the interfering item must take place concurrently with the processing of the target item (a proposal that seems compatible with the theoretical views of Grice, Boroughs, \& Canham, 1984, and Schriefers, Meyer, \& Levelt, 1990). Another account is that interference does not occur at long SOAs because there is enough time for the representation of the interfering stimulus to be inhibited by an active process before the target arrives (a proposal that seems compatible with the theoretical views of Flowers, 1990;
M. O. Glaser \& W. R. Glaser, 1982; W. R. Glaser \& Düngelhoff, 1984). This inhibition might occur through the same processes that produce negative priming: slowed responding to targets that served as distractors on the preceding trial (e.g., Driver \& Baylis, 1993; Tipper \& Driver, 1988). For either of these accounts, the prediction of little or no interference with the interfering item presented $500 \mathrm{msec}$ in advance of the target contradicts what Cowan and Barron (1987) would have expected.

In the study by Shimada (1990), SOAs between +200 and $-200 \mathrm{msec}$ were used, and the slight difference between incongruent and control (buzzer) conditions can be observed only with SOAs of $0 \mathrm{msec}$ or $+100 \mathrm{msec}$ (in which the target led slightly), not at the other delays. Thus, the little available cross-modal evidence seems consistent with the visual literature and contrary to what Cowan and Barron (1987) would have to predict for the time course of the cross-modal Stroop effect. We will see that the present results replicate the cross-modal Stroop effect, but are not consistent with Cowan and Barron's interpretation of this effect unless it is modified.

\section{EXPERIMENT 1}

\section{Method}

Subjects. Twenty-four college students ( 6 male, 18 female), who reported having normal hearing and normal or corrected-to-normal vision, participated as subjects.

Apparatus and Stimuli. Testing was conducted in a quiet room on an IBM-compatible, 486-level computer equipped with a SoundBlaster 16 audio card (Creative Labs Inc., Milpitas, CA) and the Micro-Experimental Laboratory (MEL) program, Version 2.0 (Psychology Software Tools, Pittsburgh, PA). Each subject was tested individually at a comfortable viewing distance from the computer screen. Naturally produced words in a male voice were stored digitally with a 16-bit dynamic range and were delivered to subjects via audiological (TDH-49) headphones, at an intensity measured as $68-78 \mathrm{~dB}$ with a sound level meter (A weighting, fast setting) and earphone coupler. The visual stimuli were $3 \times 3 \mathrm{~cm}$ square patches of color presented one at a time on the computer screen. As the vicwing distance was about $56 \mathrm{~cm}$, each patch subtended a visual angle of approximately $3^{\circ}$. The microphone that was provided with the MEL program (with a $600 \Omega$ impedance) was used as a voice key to record the time between the onset of a color patch and the beginning of the subject's color naming response. The color patch remained on the screen until the subject's naming response began.

There were six different color patches, corresponding to the colors red, white, blue, yellow, purple, and green, with the color selected randomly with replacement on each trial. The spoken words were drawn from the same set of colors, but always with a mismatch between the color and the word, or were drawn from a set of noncolor words matched to the colors in word frequency (Carroll, Davies, \& Richman, 1971) and syllabic structure: dry, real, best, short, fewer, and single.

Procedure. Each trial began with a small, white fixation cross. In a silent control condition, the cross was replaced by a color patch after about $200 \mathrm{msec}$. In the 0 -msec onset asynchrony condition, the visual presentation was the same but a color word was presented with an onset coincident with that of the color patch. Finally, in the 500 -msec onset asynchrony condition, the cross and color word began at the same time and the cross was replaced by a color patch $500 \mathrm{msec}$ after the onset of the word. The name of the color patch was never the same as the spoken color word. Immediately after the 
Table 1

Reaction Time in Milliseconds for Each Condition in Two Experiments

\begin{tabular}{ccccc}
\hline \multirow{2}{*}{$\begin{array}{c}\text { Word-Color } \\
\text { Onset Asynchrony }\end{array}$} & \multicolumn{4}{c}{ Auditory Stimulus } \\
\cline { 2 - 4 } & Silence & Noncolor Word & Color Word & 95\% Confidence \\
\hline & Experiment $1:$ Word Types Randomly Mixed \\
$0 \mathrm{msec}$ & 606 & 639 & 665 & $M \pm 12$ \\
$500 \mathrm{msec}$ & 601 & 579 & 573 & $M \pm 11$ \\
& Experiment & 2 2: Word Types in Separate Trial Blocks \\
$0 \mathrm{msec}$ & 556 & 576 & 622 & $M \pm 16$ \\
$500 \mathrm{msec}$ & 534 & 509 & 512 & $M \pm 13$ \\
\hline
\end{tabular}

Note-Cell standard deviations ranged from 43 to $88 \mathrm{msec}$, with the deviations for cells in any row of the table differing at most by $29 \mathrm{msec}$. Each confidence interval shown above was based on the error term from a separate one-way ANOVA conducted on the data contributing to just one row of the table. These confidence intervals for within-subjects comparisons (see Loftus \& Masson, 1994) efficiently confine the pattern of means across auditory stimulus types within a row, but should not be used for between-row comparisons

subject pronounced the name of the color patch and the experimenter entered the subject's response into the computer manually (by pressing one of six color-coded keys), the fixation cross for the next trial appeared.

Each subject received five blocks of 36 trials. The first block was a color-naming practice block in which no sounds were presented. In each of the remaining blocks, there were 12 color-word trials, 12 noncolor-word trials, and 12 silent control trials. Within each condition in a block, each of the two timing relations between the color and the word occurred on 6 of 12 trials. Because the control stimuli technically were silent sound files that were presented to the subjects in a manner just like the word stimuli, the experimental design was factorial, with auditory stimulus (color, noncolor, silent) and asynchrony between sound and word onsets ( 0 or $500 \mathrm{msec}$ ) as factors. All conditions were randomly ordered within a block. The first such block (Block 2) was counted as task practice, yielding three blocks (with 108 trials) that were included in the results.

\section{Results}

Errors. Error rates were very low. Overall, the error rate was $0.3 \%$. This rate did not include hesitations and false starts, which are much harder to code reliably. However, we estimate that the error rate including those borderline cases was between $1 \%$ and $2 \%$.

Reaction times. Reaction times $100 \mathrm{msec}$ or faster were assumed to result from extraneous noises and were eliminated from the data. Also, on the basis of histograms of the distribution of responses, reaction times larger than $1,500 \mathrm{msec}$ were considered to be outliers and were eliminated. In all, $3 \%$ of the test trials were eliminated. Each subject's mean in each condition was based on the remaining data points. The means across subjects for each condition are presented in the top half of Table 1 . The table shows that the pattern of results depended on the word-color onset asynchrony. With a simultaneous onset, reaction times were slowed $33 \mathrm{msec}$ by noncolor words and were slowed an additional $26 \mathrm{msec}$ by color as compared with noncolor words. This is slightly larger than the magnitude of the effect obtained by Cowan and Barron (1987), which was about $20 \mathrm{msec}$ per word. With a 500 -msec lead for the words, though, there was little difference between word types, which produced slightly faster responses than the silent condition.
This description of the results was initially confirmed with a $2 \times 3$, within-subjects analysis of variance (ANOVA), which produced significant main effects of both auditory stimulus type $\left[F(2,46)=3.84, M S_{\mathrm{e}}=745\right.$, $p<.04]$ and onset asynchrony $\left[F(1,23)=45.40, M S_{\mathrm{e}}=\right.$ $2,176, p<.001]$, as well as an interaction of these variables $\left[F(2,46)=28.91, M S_{\mathrm{e}}=816, p<.001\right]$. The 0 -msec condition produced slower responding and a larger effect of auditory stimulus type than did the $500-\mathrm{msec}$ condition. In the 0 -msec condition, color words led to slower mean responses than did noncolor words in 21 of the 24 subjects, which was significant by a sign test $(p<.001)$.

Planned comparisons were conducted to test the most meaningful differences between conditions. At each SOA, a comparison between color and noncolor words assessed Stroop-like interference, and a comparison between noncolor words and the silent condition assessed the effect of the presentation of a spoken word per se. At the $0-\mathrm{msec}$ SOA, both of the contrasts were significant [for the contrast of color- and noncolor-word conditions $F(1,23)=12.48, M S_{\mathrm{e}}=1,257, p<.002$; for the contrast of noncolor-word and silent conditions, $F(1,23)=14.65$, $\left.M S_{\mathrm{e}}=1,839, p<.001\right]$. At the 500-msec SOA, however, only the contrast between noncolor-word and silent conditions reached significance $\left[F(1,23)=6.59, M S_{\mathrm{e}}=1,779\right.$, $p<.02$ ], with faster performance for the noncolor-word condition, as shown in Table 1. Thus, Stroop-like interference was present only at the 0 -msec SOA, at which there was also an additional disruptive effect even of noncolor words; at a 500-msec SOA, both types of words were more beneficial than silence.

\section{Discussion}

This experiment led to a clear replication of crossmodal color-word interference effects when the onsets of the color and word were simultaneous, but not with a $500-\mathrm{msec}$ SOA that involved presentation of the word first. This pattern of interference effects across SOAs is consistent with the results of previous studies in which both the targets and the interfering items were presented visually (Flowers, 1990; M. O. Glaser \& W. R. Glaser, 
1982; W. R. Glaser \& Düngelhoff, 1984; Sugg \& McDonald, 1994), and with the cross-modal result of Shimada (1990). However, Cowan and Barron (1987) would have expected color-word interference also when the onset asynchrony was $500 \mathrm{msec}$. Prior studies of auditory memory have shown that the duration of information in a temporary auditory or phonological form of memory is certainly greater than $500 \mathrm{msec}$; estimates range from $2 \mathrm{sec}$ (Baddeley, 1986) to about $30 \mathrm{sec}$ (Cowan, 1984, 1988, 1995). Therefore, a spoken word presented $500 \mathrm{msec}$ before the to-be-named color patch should have remained active in memory when the color patch was presented. The present result therefore suggests that Cowan and Barron's notion of why interference occurs (because the spoken word and planned response occupy the buffer simultaneously) must be incorrect or incomplete.

Before we discuss alternative accounts of the crossmodal effects, it is important to replicate the pattern of findings. That was the aim of Experiment 2. The method was slightly different from that of the first experiment, in that trials with color words, noncolor words, and silence occurred in separate trial blocks rather than being randomized together in each trial block. This experimental procedure allows us to examine the role of expectations in the findings. While subjects in Experiment 1 did not know what to expect on each trial, subjects in Experiment 2 knew what the nature of the auditory presentation would be throughout most of a trial block. Therefore, if it were possible to filter out the unwanted stimuli on a semantic basis, subjects should be able to do so more easily in this second experiment.

\section{EXPERIMENT 2}

\section{Method}

Subjects. The subjects were 24 college students ( 4 male, 20 female) from the same source as in Experiment 1, though none had participated in that experiment. All subjects reported normal hearing and normal or corrected-to-normal vision.

Apparatus, Stimuli, and Procedure. The apparatus and stimuli were the same as in Experiment 1. The procedure was the same except for the arrangement of trials. There were four blocks of trials, each consisting of 6 practice trials and 36 test trials. However, the entire first block contained no sounds and was considered colornaming practice. The subsequent three blocks included a colorword block, a noncolor-word block, and a silent block, presented in an order that was counterbalanced across subjects. The 6 practice trials of each block had the same kind of auditory stimuli that would be used throughout the block.

\section{Results}

Errors. As in Experiment 1, the error rate was very low ( $0.5 \%$ across all conditions). Similar to that experiment, with hesitations and false starts included as errors, the estimated error rate was $2 \%$.

Reaction times. Reaction-time outliers were eliminated, as in Experiment 1 . In all, $5 \%$ of the test trials were eliminated.
The mean reaction times in this experiment are presented in the bottom half of Table 1 . The pattern was quite similar to that of the first experiment, although reaction times were faster overall.

Once more, an ANOVA revealed significant main effects of auditory stimulus type $\left[F(2,46)=6.74, M S_{\mathrm{e}}=1,362\right.$, $p=.003]$ and word-color onset asynchrony $[F(1,23)=$ $\left.125.66, M S_{\mathrm{e}}=1,274, p<.001\right]$, as well as an interaction of these variables $\left[F(2,46)=21.75, M S_{\mathrm{e}}=1,130, p<\right.$ $.001]$. Once more, it is clear that the color-word interference effect occurred in the 0 -msec asynchrony condition but not in the 500-msec condition. In the 0-msec condition, the color-word blocks produced slower mean responding than the noncolor-word blocks in 19 of the 24 subjects, which was significant by a sign test $(p<.01)$. The mean difference between the color- and noncolorword conditions for this onset asynchrony was $46 \mathrm{msec}$, which is $20 \mathrm{msec}$ larger than that in Experiment 1.

As in Experiment 1, planned comparisons were conducted to examine the critical differences between word conditions. The results are consistent with the findings of the first experiment. At the $0-\mathrm{msec}$ SOA, both of the contrasts were significant [for the color vs. noncolor-word conditions, $F(1,23)=15.73, M S_{\mathrm{e}}=3,244, p<.001$; for the noncolor-word vs. silent conditions, $F(1,23)=5.36$, $\left.M S_{\mathrm{e}}=2,168, p<.03\right]$. At the 500-msec SOA, only the contrast between noncolor-word and silent conditions reached significance $\left[F(1,23)=8.57, M S_{\mathrm{e}}=1,900, p<.01\right]$.

\section{Discussion}

It is clear that cross-modal color-word interference occurred even when the color- and noncolor words occurred in different blocks, so that subjects would know when to expect color-word conflicts. Therefore, the inability to predict when such conflict would occur (as in Experiment 1) does not seem critical to obtaining the effect. Moreover, as in Experiment 1, the color-word interference occurred with the 0 -msec word-color onset asynchrony but not with the $500-\mathrm{msec}$ onset asynchrony. The overall faster reaction times in this experiment probably resulted from subjects' having foreknowledge of the type of interference that would occur on each trial, but the pattern of interference effects did not change (see Table 1).

\section{GENERAL DISCUSSION}

Miles et al. (1989) and Miles and Jones (1989) failed to replicate the cross-modal Stroop effect obtained by Cowan and Barron (1987), and they called into question the existence of such effects. With an improved methodology, the present study clearly shows that the effect can be obtained. In both of the present experiments, interference from color words, as compared with noncolor words, was obtained with simultaneous onsets of the color to be named and the spoken word. However, the effect was not obtained with the word onset $500 \mathrm{msec}$ before the color onset. The 
lack of control of the word-color timing in previous studies might help to account for the empirical discrepancies between them; perhaps subtle differences in instructions, materials, or subject populations produced important differences in word-color timing. The pattern of interference effects across SOAs is similar in studies with visually presented target and interfering stimuli (Flowers, 1990; M. O. Glaser \& W. R. Glaser, 1982; W. R. Glaser \& Düngelhoff, 1984; Goolkasian, 1981; Sugg \& McDonald, 1994).

In a previous cross-modal study of color-word interference in which the relative timing of the interfering sound and color were manipulated, Shimada (1990) failed to show effects of incongruent color words relative to repetitions of the single word "white." As mentioned above, Shimada did not include a noncolor-word control condition. Nevertheless, it is worth noting that the magnitude of the difference in reaction times between the incongruent color words and a nonspeech buzzer condition in the 0 -msec condition of his study (about $20 \mathrm{msec}$ ) was roughly comparable to the magnitude of the interference from color words, relative to noncolor words, in the 0 $\mathrm{msec}$ condition of our Experiment 1 ( $26 \mathrm{msec})$. One interpretation of the results of Shimada is that it is the use of color words per se, rather than just color words drawn from the response set, that causes the cross-modal interference with color naming. That is an important hypothesis for future study. However, Shimada's result might give the impression that a repeated or redundant distractor is just as effective as a nonrepeated distractor. Contrary evidence is presented in another cross-modal interference study, that of Driver and Baylis (1993, Experiment 2). They presented printed digits to be recalled, with the concurrent presentation of nonmatching spoken digits as distractors. Some interference was caused by both redundant and changing digit distractors, but the changing distractors caused significantly more interference (see also Greenwald, 1972).

The present results yield additional information about the nature of cross-modal interference. Cowan and Barron (1987) would have expected color-word interference even with a 500-msec onset asynchrony because the word, presented first, should have remained in phonological memory at the time that the color was encountered and processed (Baddeley, 1986; Cowan, 1984, 1995). Instead, the interfering effect disappeared at this SOA, a finding that is consistent with the previous literature, as mentioned above. There are at least two ways to account for this finding.

First, it may be that it is not the short-term memory representation of the color word that interferes with color naming, but rather the processing of that color word that interferes (cf. Grice et al., 1984; Schriefers et al., 1990). For example, the process of contacting the lexical entry for the spoken word in long-term memory may conflict with the process of finding the lexical representation corresponding to the color patch. When the word leads by $500 \mathrm{msec}$, the relevant processing of the spoken word may terminate before the processing of the color patch begins, explaining the elimination of any interference between them. Schriefers et al. (1990) used this type of mechanism to explain the effects of spoken words in a picture-naming task. They found more interference with picture naming from a semantically related word than from an unrelated spoken word when the word preceded the picture by $150 \mathrm{msec}$. However, the effect was nonsignificant when the word and picture onsets were coincident, and it was totally absent when the word followed the picture by $150 \mathrm{msec}$. A different time course of effects was found if the irrelevant word and picture shared phonological, rather than semantic, characteristics. On the basis of these data, Schriefers et al. proposed that interference occurs when similar processes for the word and picture coincide. The same account could apply here, with the qualification that the time course of processing for color naming appears to differ from that for picture naming.

A second possible explanation for the absence of interference with a 500-msec SOA is as follows. An active representation of a conflicting color word could interfere with color naming (as proposed by Cowan \& Barron, 1987), but activation of the color word could be followed by a process whereby the representation is inhibited (cf. Flowers, 1990). A 500-msec SOA may be long enough for inhibition of the color word's representation to take place. As mentioned above, Driver and Baylis (1993) showed that cross-modal negative priming occurs, so it is reasonable to expect that an inhibitory process like the one that is thought to cause negative priming could have occurred in the $500-\mathrm{msec}$ SOA condition of the present experiments.

Whichever account is correct, the data show that the process of cross-modal Stroop interference is not as simple as what Cowan and Barron (1987) originally proposed. Either the account based on a temporary memory for speech is wrong or it must be supplemented by an inhibitory process that takes place when the irrelevant item is placed in memory well in advance of the relevant item. There is no known mechanism in current models of memory for speech (e.g., Baddeley, 1986; see Cowan \& Saults, 1995, for a review of related evidence) that could result in the inhibition of a speech-memory representation, but such a mechanism perhaps could be added without destroying the integrity of the models.

There is evidence from previous studies that, taken together, favors the inhibition account over the other account of the present pattern of results across SOAs. Specifically, Neill (1977) found negative priming in a visual Stroop task with a spoken response, but not with a keypress response, in which responses were faster (not slower) if the target was identical to the distractor in the immediately preceding trial. Moreover, the cross-modal Stroop effect appears to resemble the negative priming situation. There is negative priming with cross-modal presentation (Driver \& Baylis, 1993), and the cross-modal Stroop effect, like negative priming, does not appear to occur with a keypress response (Thackray \& Jones, 1971). Thus, in sum, we suspect that a spoken color word that does not match the color 
of the item to be named will interfere with color naming only if (a) the spoken word's representation is still active in memory when the color is processed, and (b) there has not been time for the representation of the word to be affected by an inhibitory process. Both qualifications were met in the 0-msec SOA condition, but, presumably, Qualification $b$ was not met in the $500-\mathrm{msec}$ SOA condition.

Another aspect of the present results that requires explanation is that, in the $0-\mathrm{msec}$ condition, even the noncolor word appeared to produce more interference than the silent condition (see Table 1). This might occur because the processing of any spoken word has some processing component(s) in common with color naming. In the 500msec condition, however, performance was slightly worse in the silent condition than in either of the word conditions. Perhaps the words served to warn subjects that a color onset was about to begin, thus increasing readiness. This type of warning effect has been obtained in previous visual studies (e.g., Flowers, 1990; Grice et al., 1984; Grice \& Gwynne, 1985). It was not obtained in the crossmodal Stroop experiment of Shimada (1990), but that is to be expected, because each trial in his study began with a fixation point $1 \mathrm{sec}$ before the color patch was presented, and this would have served as a warning signal. (In the present study, the fixation cross was $200 \mathrm{msec}$ before the color patch, which may have been too close to serve as an optimally effective warning signal.)

More work will be needed to achieve a comprehensive understanding of the effects of irrelevant speech on visual performance. It seems likely that the present effect works in a way that differs from the "irrelevant speech effect" reported by Colle and Welsh (1976) and Salamé and Baddeley (1982). In that effect, any irrelevant speech impairs memory for printed words. Salamé and Baddeley reported that the interference was worse when the irrelevant and relevant materials were phonologically similar to one another but with no effect of semantic similarity. However, Jones and Macken (1995) showed that the phonological similarity effect obtained by Salamé and Baddeley was spurious and that, with stimulus factors better controlled, there was little or no effect of the phonological similarity between the visual and auditory materials. This finding was replicated under various conditions by LeCompte \& Shaibe (1997). This general effect of irrelevant speech stands in contrast to the more specific effect of irrelevant color words in the present color-naming task. The color words were phonologically and lexically identical to words in the response set, unlike noncolor words, and perhaps this phonological or lexical similarity did make a difference in the cross-modal Stroop effect.

Another account of the cross-modal Stroop effect, which seems more plausible, would be based on the semantic similarity between the color patch and the conflicting color word presented on a trial. In this respect, the irrelevant speech effect and cross-modal Stroop effect could share a common mechanism after all. Although Salamé and Baddeley (1982) observed no role of the lexical or semantic similarity between the relevant visual and irrelevant auditory channels of information in serial recall, small but significant effects of semantics in a similar situation were observed by LeCompte, Neely, and Wilson (1997) and by Neely and LeCompte (1994). Effects of the semantic similarity of relevant visual and irrelevant auditory material also have been obtained in tasks involving reading comprehension (Martin, Wogalter, \& Forlano, 1988) and proofreading (Jones, Miles, \& Page, 1990).

Nevertheless, the large effect of semantic similarity in the cross-modal Stroop effect would appear to stand in striking contrast to the very small magnitude of any semantic component in the irrelevant speech effect. It seems likely to us, therefore, that the irrelevant speech and cross-modal color-word interference effects differ somewhat in their mechanisms. In any case, given the common occurrence of irrelevant speech in demanding work environments, there are likely to be practical as well as theoretical consequences of both of these types of irrelevant stimulus effect, or of the mechanisms underlying them.

\section{REFERENCES}

BadDeley, A. D. (1986). Working memory. Oxford: Oxford University Press, Clarendon Press.

Carroll, J. B., Davies, P., \& Richman, B. (1971). The American Heritage word frequency book. Boston: Houghton Mifflin.

COlle, H. A., \& WELSH, A. (1976). Acoustic masking in primary memory. Journal of Verbal Learning \& Verbal Behavior, 15, 17-32.

Cowan, N. (1984). On short and long auditory stores. Psychological Bulletin, 96, 341-370.

CowaN, N. (1988). Evolving conceptions of memory storage, selective attention, and their mutual constraints within the human information processing system. Psychological Bulletin, 104, 163-191.

Cowan, N. (1989a). The reality of cross-modal Stroop effects. Perception \& Psychophysics, 45, 87-88.

Cowan, N. (1989b). A reply to Miles, Madden, and Jones (1989): Mistakes and other flaws in the challenge to the cross-modal Stroop effect. Perception \& Psychophysics, 45, 82-84.

Cowan, N. (1995). Attention and memory: An integrated framework $(\mathrm{Ox}-$ ford Psychology Series, No. 26). New York: Oxford University Press.

Cowan, N., \& BARRon, A. (1987). Cross-modal, auditory-visual Stroop interference and possible implications for speech memory. Perception \& Psychophysics, 41, 393-401.

Cowan, N., \& Saults, J. S. (1995). Memory for speech. In H. Winitz (Ed.), Human communication and its disorders (Vol. 4, pp. 81-170). Timonium, MD: York Press.

DrIVER, J., \& BAYLIS, G. C. (1993). Cross-modal negative priming and interference in selective attention. Bulletin of the Psychonomic Society, 31, 45-48.

Flowers, J. H. (1990). Priming effects in perceptual classification. Perception \& Psychophysics, 47, 135-148.

Glaser, M. O., \& Glaser, W. R. (1982). Time course analysis of the Stroop phenomenon. Journal of Experimental Psychology: Human Perception \& Performance, 8, 875-894.

Glaser, W. R., \& Düngelhoff, F.-J. (1984). The time course of picture-word interference. Journal of Experimental Psychology: Human Perception \& Performance, 10, 640-654.

Goolkasian, P. (1981). Retinal location and its effect on the processing of target and distractor information. Journal of Experimental Psychology: Human Perception \& Performance, 7, $1247-1257$.

Green, E. J., \& Barber, P. J. (1981). An auditory Stroop effect with judgments of speaker gender. Perception \& Psychophysics, 30, 459-466.

Greenwald, A. G. (1972). Evidence of both perceptual filtering and response suppression for rejected messages in selective attention. Journal of Experimental Psychology, 94, 58-67.

Grice, G. R., Boroughs, J. M., \& Canham, L. (1984). Temporal dy- 
namics of associative interference and facilitation produced by visual context. Perception \& Psychophysics, 36, 499-507.

GricE, G. R., \& GWYNN, J. W. (1985). Temporal characteristics of noise conditions producing facilitation and interference. Perception \& Psychophysics, 37, 495-501.

JONES, D. M., \& MACKEN, W. J. (1995). Phonological similarity in the irrelevant speech effect: Within- or between-stream similarity? Journal of Experimental Psychology: Learning, Memory, \& Cognition, 21, 103-115.

Jones, D. M., Miles, C., \& PAGE, J. (1990). Disruption of proofreading by irrelevant speech: Effects of attention, arousal, or memory? $A p$ plied Cognitive Psychology, 4, 89-108.

LeCompte, D. C., NeEly, C. B., \& Wilson, J. R. (1997). Irrelevant speech and irrelevant tones: The relative importance of speech to the irrelevant speech effect. Journal of Experimental Psychology: Learning, Memory, \& Cognition, 23, 472-483.

LECoMPTE, D. C., \& ShajBe, D. M. (1997). On the irrelevance of phonology to the irrelevant speech effect. Quarterly Journal of Experimental Psychology, 50A, 100-118.

LofTus, G. R. \& Masson, M. E. J. (1994). Using confidence intervals in within-subject designs. Psychonomic Bulletin \& Review, 1, 476-490.

MACLEOD, C. M. (1991). Half a century of research on the Stroop effect: An integrative review. Psychological Bulletin, 109, 163-203.

MacLEOD, C. M. (1992). The Stroop task: The "gold standard" of attentional measures. Journal of Experimental Psychology: General, 121, 12-14.

Martin, R. C., Wogalter, M. S., \& Forlano, J. G. (1988). Reading comprehension in the presence of unattended speech and music. Journal of Memory \& Language, 27, 382-398.

MCClaIN, L. (1983). Stimulus-response compatibility affects auditory Stroop interference. Perception \& Psychophysics, 33, 266-270.

Miles, C., \& JoNEs, D. M. (1989). The fallacy of the cross-modal Stroop effect: A rejoinder to Cowan (1989). Perception \& Psychophysics, $45,85-86$.
Miles, C., Madden, C., \& Jones, D. M. (1989). Cross-modal, auditoryvisual Stroop interference: A reply to Cowan and Barron (1987). Perception \& Psychophysics, 45, 77-81.

NeELy, C. B., \& LeCompTE, D. C. (1994, November). The role of semantic relatedness in the irrelevant speech effect. Poster presented at the annual meeting of the Psychonomic Society, St. Louis.

NEILL, W. T. (1977). Inhibitory and facilitatory processes in selective attention. Journal of Experimental Psychology: Human Perception \& Performance, 3, 444-450.

SalamÉ, P., \& Baddeley, A. (1982). Disruption of short-term memory by unattended speech: Implications for the structure of working memory. Journal of Verbal Learning \& Verbal Behavior, 21, 150-164.

SCHRIEFERS, H., MEYER, A. S., \& LEVELT, W. J. M. (1990). Exploring the time course of lexical access in language production: Picture-word interference studies. Journal of Memory \& Language, 29, 86-102.

SHIMADA, H. (1990). Effect of auditory presentation of words on color naming: The intermodal Stroop effect. Perceptual \& Motor Skills, 70, 1155-1161.

STROOP, J. R. (1935). Studies of interference in serial verbal reactions. Journal of Experimental Psychology, 18, 643-662.

SugG, M. J., \& McDonald, J. E. (1994). Time course of inhibition in color-response and word-response versions of the Stroop task. Journal of Experimental Psychology: Human Perception \& Performance, 20, 647-675.

Thackray, R. I., \& JonEs, K. N. (1971). Level of arousal during Stroop performance: Effects of speed stress and "distraction." Psychonomic Science, 23, 133-135.

TIPPER, S. P., \& DRIVER, J. (1988). Negative priming between pictures and words in a selective attention task: Evidence for semantic processing of ignored stimuli. Memory \& Cognition, 16, 64-70.

(Manuscript received December 12, 1996; revision accepted for publication May 12, 1997.) 